\title{
LA VALORACIÓN DE LA VIDA, LA SUBJETIVACIÓN DEL EMBRIÓN Y EL DEBATE SOBRE EL ABORTO: APORTES DESDE UNA PERSPECTIVA CRÍTICA
}

José Manuel Morán Faúndes ${ }^{1}$

Resumen: El artículo analiza críticamente la forma en la que se planteado el debate ético y jurídico en torno al aborto, como un conflicto de derechos entre el embrión y la mujer, mostrando los modos en los que se ha construido la figura del embrión, como un sujeto susceptible de valoración moral y protección jurídica. En particular, se discute la posición que asume al cigoto indefectiblemente como un sujeto moral, por el hecho de poseer un genoma distinto del de sus progenitores, otorgándole un estatuto jurídico equivalente al de las mujeres. Así, se establece una crítica en torno al modo como esta posición, a través del uso de un lenguaje científico que se presenta como objetivo, ha tendido a invisibilizar las formas sociales y culturales que construyen la valoración de la vida.

Palabras clave: aborto inducido, embrión, feto, mujeres, cultura, genética

The value of life, the embryo subjectivity and the debate about abortion: contributions from a critical perspective

Abstract: This paper analyzes critically the way in which the ethical and legal debate about abortion is posed, as a conflict of rights between the embryo and the woman, showing the ways in which the figure of the embryo is built, as a subject susceptible of moral value and legal protection. In particular, the view sustaining the zygote as unfailing moral subject is discussed, by the fact of having a specific genome, different from progenitors, giving it a legal statute equivalent to women. Thus, a critique is stablished towards the way this view, through scientific language, presented as objective, has hold out to make invisible the cultural and social ways in which the value of life is built.

Key words: induced abortion, embryo, fetus, women, culture, genetics

A valoraçáo da vida, a subjetivaçáo do embriáo e o debate sobre o aborto: aportes a partir de uma perspectiva crítica

Resumo: $\mathrm{O}$ artigo analisa criticamente a forma com a qual se propõe o debate ético e jurídico em torno do aborto, como um conflito de direitos entre o embrião e a mulher, mostrando os modos em que foi construída a figura do embrião, como um sujeito suscetível de valoração moral e proteção jurídica. Em particular, se discute a posiçáo que assume o zigoto incontestavelmente como um sujeito moral, pelo fato de possuir um genoma distinto de seus progenitores, outorgando-lhe um estatuto jurídico equivalente ao das mulheres. Assim, se estabelece uma crítica em torno do modo como esta posiçáo, por meio do uso de uma linguagem científica que se apresenta como objetivo, tendeu a tornar invisível as formas sociais e culturais que constroem a valoração da vida.

Palavras-chave: aborto induzido, embriâo, feto, mulheres, cultura, genética

\footnotetext{
${ }^{1}$ Becario CONICET del Centro de Investigaciones Jurídicas y Sociales (CIJS) de la Universidad Nacional de Córdoba (UNC), Argentina Correspondencia: jmfmoran@gmail.com
} 


\section{Introducción}

Las consideraciones bioéticas y jurídicas respecto del embarazo y su interrupción voluntaria suelen ser un tema de amplio debate y fuertes controversias. Estos debates suelen remitir a posiciones morales, filosóficas, jurídicas y políticas enfrentadas, en especial en lo que refiere a los cuidados y derechos del embrión (y posteriormente del feto) y de las mujeres. Si bien las discusiones en torno a esta temática son múltiples, uno de los lugares más comunes desde los que se debaten estos asuntos remite al estatuto moral y jurídico del embrión ${ }^{2}$. En particular, quienes tienen reservas respecto de la legitimidad de cualquier intervención que induzca a un aborto y defienden posiciones más bien restrictivas en esta materia suelen asumir la posición de que el embrión es ya un sujeto susceptible de protección desde el momento de la fecundación. Así, esta posición entra en conflicto con la de quienes asumen una postura más permisiva y focalizan su atención en el derecho y la autonomía de las mujeres por sobre la protección del embrión, al menos hasta ciertos estadios de su desarrollo. En este sentido, el debate sobre el aborto queda entrampado en el momento en que se lo sitúa como una disputa entre los derechos de la mujer (a la salud, al propio cuerpo, a su vida, etc.) y el derecho a la vida desde la fecundación.

Sin embargo, para llegar a pensar el debate en esos términos ha sido necesario dar un paso anterior, el que generalmente es invisibilizado e incluso negado por algunos: para pensar el aborto en términos de un conflicto de derechos ha sido necesario construir antes al embrión como un "sujeto". Tomando esto en consideración, en las siguientes líneas buscaré discutir críticamente la forma en la que se ha tendido a plantear el debate ético y jurídico en torno al aborto como un conflicto de derechos, mostrando los modos en los que se ha construido la figura del embrión y del feto como un sujeto susceptible de valoración moral y protección jurídica desde la fecundación. Para estos fines, consideraré los principales aportes que las ciencias sociales y las humanidades han realizado

\footnotetext{
${ }^{2}$ Desde algunas perspectivas científicas y bioéticas se realiza una diferenciación entre el preembrión, considerado como aquel que aún no ha sido implantado, y el embrión(1). Sin desconocer los debates en torno al uso de estos términos, a lo largo del presente artículo no haré distinción entre ambos conceptos, con el fin de simplificar el argumento.
}

en esta materia, en especial desde el enfoque de la antropología, la sociología y los estudios culturales. Considero entonces que las perspectivas que estas disciplinas han aportado deben ser consideradas dentro de los debates bioéticos en materia de aborto, puesto que permiten dilucidar las formas en las que el propio debate se ha construido, además de dar luces acerca del insoslayable rol de los procesos culturales y las negociaciones sociales y políticas que atraviesan al mismo.

\section{La valoración de la vida como un proceso cul- tural}

Cada sociedad y cada cultura negocian de manera distinta los umbrales que determinan el momento en que la vida comienza a ser considerada como susceptible de protección(2). La antropología ha demostrado que en muchas sociedades no industrializadas el inicio biológico de la vida no coincide necesariamente con el inicio de la valoración de esa vida(3-6). En ciertas culturas, el inicio de la vida suele ser asociado al momento del parto biológico, por ser este el primer instante en que es posible visibilizar al niño o niña, mientras que su aceptación social, esto es, la entrada de esa nueva vida a la comunidad, puede ocurrir en un momento posterior, como cuando se cumplen ciertos ritos, cuando ocurren determinados eventos simbólicos de importancia para la comunidad o cuando se alcanza un cierto estado de maduración. En palabras de la antropóloga Lynn Morgan(3), en múltiples culturas el "parto biológico" está separado del "parto social". En algunos lugares, por ejemplo, el ingreso simbólico de una nueva vida a la comunidad ocurre recién cuando se le asigna un nombre al bebé, cuando se realiza la perforación de una de sus orejas, cuando se le circuncida, etc., ritos que pueden ocurrir a los pocos días o a los años luego del parto biológico. De este modo, en ciertas sociedades, antes del nacimiento biológico, ni el embrión ni el feto son considerados todavía una nueva vida, ni menos aún sujetos susceptibles de protección o valoración moral.

En las sociedades occidentales industrializadas, en cambio, la situación es distinta. Desde hace unas pocas décadas venimos atravesamos una dinámica social y política en la que hemos tendido a adelantar el momento simbólico en que valoramos y admitimos esa nueva vida como parte de la comu- 
nidad. En gran medida, esto se debe a las nuevas tecnologías de visualización que desde mediados del siglo XX nos han permitido observar embriones y fetos antes del nacimiento. Esta "visibilidad" adquirida por el embrión y el feto dentro del útero de la mujer ha transformado las percepciones respecto de estos, produciendo cambios en la valoración subjetiva que les asignamos, dada la atención que se les otorga(7-11). Como indica Lynn Morgan(3), las tecnologías de visualización han adelantado el parto social en Occidente. Por supuesto, este fenómeno ha ocurrido con una relativa ambigüedad: aunque hoy le asignamos nombres a los hijos antes de su nacimiento, oficialmente el nombre queda registrado y oficializado recién tras el parto; pese a que valoramos la vida fetal, los registros de mortalidad oficiales solo cuentan las muertes de aquellos que murieron tras el parto, y no antes de este; para diversos efectos, una mujer embarazada cuenta como una sola persona, y no como dos, etc. Es decir, atravesamos actualmente un proceso ambiguo de adelantamiento del parto social, en el que valoramos la vida antes del nacimiento, sin desprendernos del todo de la idea de que el parto biológico constituye un momento simbólico central que marca el ingreso a la comunidad.

De este modo, es posible ver que la valoración del embrión como un sujeto, como un miembro de la comunidad, es una operación cultural, una construcción social que nada tiene que ver con una verdad neutral y objetiva, sino con los procesos de negociación que cada sociedad realiza. El problema es que en las sociedades occidentales industrializadas hemos tendido a negar ese carácter construido que tiene la valoración de la vida, disfrazándolo bajo la apariencia de una verdad científica e irrefutable. Pero ver un feto mediante una ecografía o un embrión mediante un microscopio es distinto a asignarle un estatus moral, un carácter de persona o de sujeto de derechos. La asignación de la categoría de "sujeto" a dicho embrión o feto es una imputación de sentido, una forma subjetiva de otorgarle un carácter moral y/o jurídico, un modo de significar lo que se ve en una ecografía y no un dato observable de manera objetiva en la imagen(12).

\section{La valoración del cigoto y el discurso genético}

Pese a que la subjetivación del embrión (esto es, la acción de otorgarle el estatus de sujeto) es una acción de poder, un acto mediado por la cultura y construido socialmente, quienes rechazan el derecho al aborto muchas veces suelen amparar sus argumentos en la afirmación de que el embrión es ya, objetiva e incuestionablemente, un sujeto moralmente valorable, susceptible de protección médica y jurídica incluso desde el momento de la fecundación. Y es que el hecho de que el cigoto contenga ya la información genética que se replicará en cada una de las células que se desarrollen en el proceso de formación del cuerpo del individuo constituye para algunos la prueba científica de que la vida individual comenzaría a partir de la fecundación, y eso los lleva a argumentar que la vida del cigoto es ya una vida susceptible de valoración moral y cuidado. Así, para algunos, la fecundación se ha transformado en un instante que pareciera marcar de manera aparentemente irrefutable la aparición de un sujeto, de una persona.

Esta asignación de valor al óvulo fecundado se debe, en parte, como hemos dicho, a las nuevas tecnologías de visualización que le han otorgado centralidad al cigoto, al permitir ver el proceso de fecundación mediante imágenes producidas en laboratorios. Pero también se alimenta de los imaginarios genetistas que desde mediados del siglo XX se han popularizado, y que han tendido a producir la idea de que somos seres esencialmente genéticos(13).

Como indica el sociólogo inglés Nikolas Rose(14), el advenimiento de la genética tuvo importantes consecuencias que transformaron el estilo de pensamiento del campo biológico, así como nuestra propia comprensión de la vida. Una de estas transformaciones es lo que él denomina como "molecularización de la vida”. A partir de la década del treinta, y gracias a las nuevas tecnologías ópticas y las incipientes investigaciones en genética, la biología empezó a visualizar los objetos de su estudio a un nivel submicroscópico (entre $10^{-6}$ y $10^{-7}$ $\mathrm{cm}$ ). Las leyes y funciones que regularían la vida empezaron a verse y pensarse a escala molecular y, por lo tanto, la vida misma empezó a pensarse en ese nivel. En otras palabras, el desarrollo de la genética transformó la epistemología científica, 
que tradicionalmente había comprendido sus objetos principalmente a nivel de las grandes masas de materia, esto es, de los tejidos, los órganos, los flujos sanguíneos, etc., desplazándose hacia una forma de pensamiento que comenzó a entenderlos cada vez más a escala molecular.

Pero la molecularización de la vida introducida por la genética no solo impactó en el nivel en el cual comenzaron a observarse los objetos de la biología. Además, siguiendo a Georges Canguilhem(15), los antecedentes de la genética forjaron un cambio lingüístico en las mismas ciencias biológicas. Las formulaciones científicas acerca de la vida, esto es, de las leyes y mecanismos que la gobiernan, dejaron en ese momento de ser pensadas en términos del lenguaje y los conceptos de la mecánica, la física y la química clásicas. A partir de mediados del siglo XX, nociones como "información", "código", "programa", "instrucción” y "desciframiento" pasaron a dominar el conocimiento de la vida. La genética introdujo en la biología una nueva forma de pensar la vida en sí: "Para comprender la vida es preciso proponerse, antes de leerla, desencriptar su mensaje" (15:386). Así, en la actual era de la genética, los genes han adquirido el carácter de entidades que contienen la información del programa predeterminado a través del cual operaría y se regularía la vida misma. Los genes son pensados por la biología contemporánea como entidades en sí mismas, cuya información es necesario decodificar y descifrar para comprender las formas en las que operan los procesos propios de la vida(10). Comprender cómo se desarrolla la vida, cuáles son las normas naturales que la gobiernan, implica entonces descifrar el código inscripto en los genes. La vida en sí misma, siguiendo a la antropóloga Sarah Franklin, ha sido reducida al gen, y el gen a información: "hemos arribado a una secuencia simple: la naturaleza se transformó en biología y la biología en genética, y a través de ésta la vida misma devino en información reprogramable"3(13:190). De este modo, el desarrollo de la genética y sus transformaciones en el campo de la biología ha impactado en nuestras formas de pensarnos en tanto seres biológicos, así como en nuestros modos de relacionarnos con nosotros y con los otros(16).

${ }^{3}$ La traducción es propia.
Esta idea de que los genes contienen la información del "programa de la vida", nutre el argumento contemporáneo de quienes suelen rechazar el aborto amparándose en la idea de que la vida individual, y su consecuente valoración, comenzaría con la fecundación. Pero pensar que la vida individual comienza en la fecundación, dado que es ahí cuando se forma el genoma humano, y asumir una consecuente valoración moral absoluta de la vida desde ese instante, implica asumir un reduccionismo que establece que los seres humanos somos esencialmente genes, que nuestra vida es una vida básicamente genética y que nuestro ADN sería determinante de nuestra condición de individualidad. Asimismo, implica asumir que somos valorables en tanto somos seres genéticos. En otras palabras, es entender a los seres humanos bajo un prisma esencialista, como un simple conjunto de códigos pre programados (los genes), y no como entidades complejas en cuyas formas de actuar y pensar se interconectan estructuras biológicas con medios sociales y culturales(17). Es negar que gran parte de nuestras acciones, sensaciones, sentimientos, decisiones, etc., están atravesados por nuestra crianza, por nuestra interacción con el entorno y por las formas culturales en las que significamos el mundo, y no por un simple código genético predeterminado. Por esto, este imaginario genetista entraña una nueva forma de reduccionismo, de esencialización disfrazada de biología, en lo que la bióloga Donna Haraway(10) denomina "fetichismo genético".

Al ver en un microscopio el proceso de fecundación, la imagen no nos muestra una persona, ni menos un sujeto de derechos, solo dos células que se unen. El carácter de persona es una idea política y socialmente construida, no una verdad científica. Así, no hay nada de objetivo en afirmar que un cigoto es un sujeto. Solo es una imputación de sentido, una forma subjetiva de asignarle valor moral y jurídico a una célula, basándose en el imaginario genetista que afirma que los genes son todo, que los genes representan la última verdad de nuestra existencia, un nuevo dios secularizado.

Sin embargo, quienes se oponen al derecho al aborto argumentando que el cigoto es ya una persona, dada su estructura genética, suelen subjetivar al embrión negando la operación política que efectúan, produciendo con esto un imagi- 
nario que separa a la mujer y al producto de la fecundación como dos sujetos "objetivamente" diferenciados(18-19). Así, otorgan al embrión la cualidad de sujeto y, como tal, de persona susceptible de protección, al tiempo que invisibilizan a las mujeres y les otorgan un estatus moral y jurídico equivalente al de una célula como es el cigoto. Esta separación instaura la apariencia de que el producto de la fecundación constituiría un ser autónomo respecto de la mujer, instituyendo límites entre ambos bajo la apariencia de la naturalidad y la objetividad. Así, amparándose en un imaginario genetista que ha otorgado autonomía al producto de la fecundación, los cuerpos de las mujeres terminan siendo invisibilizados, relegándolas al lugar de meros contenedores, responsables penalmente de garantizar la vida de ese embrión subjetivado.

Pero el embrión no solo es construido como un simple sujeto por parte de quienes rechazan el derecho al aborto basándose en consideraciones de índole genetista. Es construido específicamente como una potencial víctima, con lo cual convierten a las mujeres en potenciales victimarias(20). Como señala la jurista italiana Tamar Pitch(21), es justamente mediante la construcción del embrión como una víctima potencial de la mujer que es posible elevar su estatus al de un sujeto de derechos. La subjetivación del embrión, en este sentido, vuelve sospechosa la autonomía de las mujeres, su capacidad para decidir, evocando el antiguo sistema patriarcal de distribución desigual del poder que sitúa a las mujeres en un lugar jerárquicamente inferior al de los hombres, volviendo sospechosa su capacidad de actuar autónomamente. La idea de que en su interior habita una vida distinta a la de ella desmonta la posibilidad de actuar sobre el propio cuerpo de manera autónoma, y le imputa una responsabilidad, incluso en términos penales, sobre la vida de un tercero, más allá de su voluntad y su deseo. Así, bajo la apariencia de objetividad científica, se instituye una forma de tutela sobre los cuerpos y las subjetividades de las mujeres.

\section{Consideraciones finales}

Asumir que las posiciones que consideran al cigoto como un individuo susceptible de valoración moral y protección jurídica representan produc- ciones culturales y políticas, y no verdades en sí, nos obliga a resituar el debate en torno al aborto a partir de otros términos. Más que preguntarnos cuándo comienza la vida y desde cuándo esta debería ser valorada — pregunta por lo demás imposible de responder de un modo absoluto-, conviene preguntarnos cómo estamos construyendo el debate en torno al aborto, en qué ideas y creencias socioculturales se basan nuestras apreciaciones éticas y jurídicas al respecto, y qué consecuencias tienen estas construcciones en nuestras formas de pensar y significar a los sujetos involucrados en el debate.

Antes de debatir el aborto en términos de un conflicto de derechos entre el embrión y la mujer, debemos sincerar los modos en que hemos situado el debate en ese terreno, haciendo uso de un lenguaje científico para esconder los modos arbitrarios en los que hemos construido al embrión como un sujeto de derechos a costa de la autonomía de las mujeres. De este modo, antes de buscar principios bioéticos universales y abstractos que nos permitan dilucidar cuándo comenzaría la vida y desde cuándo esta sería susceptible de valoración moral y protección jurídica, es necesario considerar críticamente las formas en las que muchos de esos principios se construyen, esto es, sobre la base de un conocimiento imbricado en prejuicios, creencias e ideas social y culturalmente construidas, aun cuando dicho conocimiento niegue la mediación cultural que lo atraviesa.

Dado que la biología no es el cuerpo, sino un discurso sobre el cuerpo(10), el conocimiento científico debe ser comprendido como un conocimiento mediado por los imaginarios, formas de categorización, creencias, etc., que constituyen nuestra subjetividad y nos permiten significar el mundo. El conocimiento científico acerca de la vida, en este sentido, incluyendo sus fronteras, su inicio y su fin, es siempre una producción epistémica y política, y no un conjunto de proposiciones neutrales e inmunes al poder, a la cultura y a la historia.

Por supuesto, esta crítica no implica rechazar la ciencia como forma de conocer el mundo, ni invisibilizar al embrión o al feto como si no existiesen, sino asumir que todo significado y valoración que le asignamos al embrión es una representa- 
ción, una construcción social que tiene consecuencias sobre el cuerpo de las mujeres, y no una forma imparcial y objetiva de pensar en la vida embrional. Asimismo, entender el conocimiento científico como un saber mediado por la cultura, por las experiencias y subjetividades de quienes producen dicho conocimiento(22), no es lo mismo que asumir que todo conocimiento es "inventado" por la ciencia(10). Por el contrario, implica reconoce que la única forma de producir un conocimiento fidedigno y sólido es a través de la producción colectiva del saber, formada por distintos puntos de vista que incluyan, entre otros, las perspectivas, valoraciones y percepciones de las mujeres involucradas. No se trata de negar los significados y los cuerpos, sino de construir significados y cuerpos que tengan una oportunidad en el futuro(23). Un verdadero compromiso ético y político con la superación de las desigualdades, en particular las de género, implica en este sentido desnaturalizar las ideas que continúan colocando a las mujeres en el lugar de sujetos cuya autonomía hay que tutelar, amparadas bajo el disfraz de la objetividad científica.

\section{Agradecimientos}

El presente artículo se desarrolló en el marco de una investigación doctoral realizada con el apoyo de una beca del Consejo Nacional de Investigaciones Científicas y Técnicas (CONICET-Argentina). Agradezco los comentarios realizados al presente texto por María Angélica Peñas Defago. Sin perjuicio de lo anterior, todo lo dicho en este artículo es plena responsabilidad mía. 


\section{Referencias}

1. Faúndes A, Barzelatto J. El drama del aborto. En busca de un consenso. Buenos Aires: Paidós; 2011.

2. LiPuma E. Modernity and Forms of Personhood in Melanesia. In: Lambek M, Strathern A, eds. Bodies and Persons. Comparative Perspectives from Africa and Melanesia. London: Cambridge University Press; 1998: 53-79.

3. Morgan, LM. When does life begin? A cross-cultural perspective on the personhood of fetuses and young children. In Doerr E, Prescott JW, eds. Abortion and Fetal "Personhood". Long Beach: Centerline Press; 1989: 97-114.

4. Susnik B. Interpretación etnocultural de la complejidad sudamericana antigua. El hombre, persona y agente ergológico. Asunción: Museo Etnográfico Andrés Barbero; 1995.

5. Conklin BA, Morgan LM. Babies, Bodies, and the Production of Personhood in North America and a Native Amazonian Society. Ethos 1996; 24(4): 657-694.

6. Mader E. Metamorfosis del poder. Persona, mito y visión en la sociedad Shuar y Achuar (Ecuador, Perú). Quito: Ediciones Abya-Yala; 1999.

7. Petchesky RP. Fetal Images: The Power of Visual Culture in the Politics of Reproduction. Feminist Studies 1987; 13(2): 263-292.

8. Franklin S. Fetal Fascinations: New Dimensions to the Medical-scientific Construction of Fetal Personhood. In: Franklin S, Lury C, McNeil M, eds. Off-centre: Feminism and Cultural Studies. London: HarperCollins; 1991: 190-205.

9. Duden B. Disembodying Women. Pespectives on Pregnancy and the Unborn. Cambridge/London: Harvard University Press; 1993.

10. Haraway D. ModestWitness@Second_Millennium.FemaleMan_Meets_OncoMouseTM. New York: Routledge; 1997.

11. Morgan LM. Icons of Life. A Cultural History of Human Embryos. Berkeley/Los Angeles/London: University of California Press; 2009.

12. Duden B. El concepto de 'Vida': un ídolo moderno y una amenaza para las mujeres embarazadas. DUODA Revista d'Estudis Feministes 1996; 11: 79-96.

13. Franklin S. Life Itself. Global Nature and the Genetic Imaginary. In: Franklin S, Lury C, Stacey J. Global Nature, Global Culture. London: Sage; 2000: 188-227.

14. Rose N. Politics of life itself. Biomedicine, power and subjectivity in the Twenty-First Century. Nueva Jersey: Princeton University Press; 2007.

15. Canguilhem G. Estudios de historia y de filosofia de las ciencias. Buenos Aires: Amorrortu; 2009.

16. Braidotti R. Biomacht und Nekro-Politik. Überlegungen zu einer Ethik der Nachhaltigkeit. Springerin. Hefte für Gegenwartskunst 2007; 8(2): 18-23.

17. Fausto-Sterling A. Cuerpos sexuados. Barcelona: Melusina; 2006.

18. Phelan P. Unmarked. The Politics of Performance. London / New York: Routledge; 1996.

19. Ploeg IVD. 'Only Angels Can Do Without Skin': On Reproductive Technology's Hybrids and the Politics of Body Boundaries. Body \& Society 2004; 10(2/3): 153-181.

20. Casper MJ y Morgan LM. Constructing Fetal Citizens. Anthropology News 2004; Dec: 17-18.

21. Pitch T. Un derecho penal para dos. La construcción juridica de género, sexo y sexualidad. Madrid: Trotta; 2003.

22. Cárcamo Quezada C. Verdad científica, poder y obediencia. Acta Bioethica 2011; 17(2): 165-169.

23. Haraway D. Ciencia, cyborgs y mujeres. La reinvención de la naturaleza. Madrid: Cátedra; 1995.

Recibido: 8 de agosto de 2013

Aceptado: 27 de mayo de 2014 